\title{
Renal transplantation in infants
}

\author{
Hannu Jalanko ${ }^{1}$ - Ilkka Mattila ${ }^{2}$ Christer Holmberg ${ }^{1}$
}

Received: 2 December 2014 / Revised: 27 May 2015 / Accepted: 8 June 2015 / Published online: 27 June 2015

(C) IPNA 2015

\begin{abstract}
Renal transplantation (RTx) has become an accepted mode of therapy in infants with severe renal failure. The major indications are structural abnormalities of the urinary tract, congenital nephrotic syndrome, polycystic diseases, and neonatal kidney injury. Assessment of these infants needs expertise and time as well as active treatment before RTx to ensure optimal growth and development, and to avoid complications that could lead to permanent neurological defects. RTx can be performed already in infants weighing around $5 \mathrm{~kg}$, but most operations occur in infants with a weight of $10 \mathrm{~kg}$ or more. Perioperative management focuses on adequate perfusion of the allograft and avoidance of thrombotic and other surgical complications. Important long-term issues include rejections, infections, graft function, growth, bone health, metabolic problems, neurocognitive development, adherence to medication, pubertal maturation, and quality of life. The overall outcome of infant RTx has dramatically improved, with long-term patient and graft survivals of over 90 and $80 \%$, respectively.
\end{abstract}

Keywords Infant · Kidney transplantation · Growth · Infections $\cdot$ Neurocognitive development

Hannu Jalanko

hannu.jalanko@hus.fi

1 Department Pediatric Nephrology and Transplantation, Children's Hospital, University of Helsinki and Helsinki University Hospital, PO Box 281, Helsinki 00290, Finland

2 Department of Cardiac and Transplantation Surgery, Children's Hospital, University of Helsinki and Helsinki University Hospital, Helsinki, Finland

\section{Introduction}

The first kidney transplantations (RTx) to infants (0-24month-old children) were performed in the 1960s in Minneapolis $[1,2]$. The long-term results were at first modest and skepticism was expressed on the rationality of treating small children with severe renal failure. In the 1980s, technical refinements in dialysis therapy and post-RTx immunosuppressive medication dramatically improved the overall results of renal replacement therapy (RRT) in children and adults, and also led to a gradual acceptance of these therapies for infants with end-stage renal disease (ESRD).

Infants still form a minor group in pediatric RTx programs. The incidence of children needing RRT before the age of 2 years is low (7-8 per million age-related population) [3]. In a survey from the UK and Ireland, infants accounted for only $2.8 \%(19 /$ 675) of pediatric patients with ESRD [4]. In the North American Pediatric Renal Trials and Collaborative Studies (NAPRTCS) registry data on 10,632 RTx recipients, children $<24$ months accounted for $5.3 \%$ of pediatric recipients [5]. In a recent report from Europe, Australia, New Zealand, and Japan, very few of the children who already needed RRT during the neonatal period were transplanted before the age of 12 months, and $80 \%$ of these children were still on dialysis at the age of 24 months [3]. There is, however, center-based variation and many large specialized centers perform RTx for younger infants.

\section{Recipient characteristics}

The major indications for infant RTx are congenital abnormalities of the urinary tract (CAKUT), congenital nephrotic syndrome (CNS), neonatal cortical necrosis due to thrombosis, and autosomal recessive polycystic kidney disease (ARPKD) [6]. A small proportion of patients have a diagnosis seen in 
older children, such as hemolytic uremic syndrome and oxalosis. It is important to note that acute kidney injury in the neonatal period, particularly in premature infants, often recovers and rarely leads to ESRD and RTx in infancy. Similarly, most infants with CAKUT show slow progression and the patients manage into adolescence or adulthood without RRT [7]. The progression of renal failure in inherited CNS may also be slow and RTx can be performed at the age of 2-5 years.

Active treatment of infants before RTx is important to ensure optimal growth and development as well as to avoid complications (thromboses, septic infections) that could lead to permanent neurological defects. Nutritional therapy, adequate calcium and vitamin D supplementation, phosphatebinding medication, anemia and infection, as well as management of hypertension and proteinuria are required to prevent the progression of renal failure [8]. Peritoneal dialysis (PD) is mostly used for ESRD management before RTx [9] and hemodialysis (HD) is reserved for those with problems in PD. However, in patients with oxalosis, organic acidemias, extensive history of abdominal surgery, poor socioeconomic circumstances, and fear for familial non-adherence, HD is the preferred treatment modality. Home PD in an anuric infant is also demanding, and improvements in pediatric HD may increase its use in coming years.

Absolute contraindications for RTx are uncontrolled malignancy and infection, as is the case with older patients. Children with a history of Wilms tumor have traditionally been transplanted 2 years after the end of cancer therapy (European guidelines), but recent data suggest that patients with a low-risk tumor who remain relapse-free for 6 months after treatment might be considered for transplantation [10]. Up to $40 \%$ of infants with ESRD have CAKUT and the anomalies, which were previously regarded as a contraindication to RTx, may affect the long-term kidney graft function and survival. Preoperative assessment of the bladder function with urodynamic studies is crucial in CAKUT patients. No consensus exits whether augmentation of the bladder should be performed pre- or posttransplant in children needing it. In our unit, infants usually undergo ureterocystoplasty before transplantation, whereas intestinal cystoplasty and Mitrofanoff conduit are performed after RTx, if needed. According to recent reports, CAKUT patients manage quite well after RTx and augmentation does not seem to affect the overall graft or patient survivals [11-14].

More than one-third of pediatric patients with ESRD have co-morbidities, such as chromosomal abnormalities, syndromic diagnosis, cerebral palsy, heart disease, and developmental delay, which may severely worsen the life quality and overall prognosis after RTx [4]. Withholding treatment from these infants is a difficult ethical question with no simple answer [6]. In general, attitudes have shifted with time and more handicapped patients are currently accepted for RRT. An individualized decision is usually made by a multidisciplinary team from the transplant center before the commencement of chronic dialysis.
The practice in most transplant centers is to start chronic dialysis only in those infants who are regarded as candidates for transplantation. The crucial question is how and to what extent the child and the family benefits from the operation [15].

\section{Donor characteristics}

A kidney from either of the parents is often used in infant RTx. According to a NAPRTCS report from the US, a living donor (LD) kidney was used in about $50 \%$ of all pediatric RTx and in $74 \%$ of infant RTx [5]. In the Eurotransplant region, the percentage of LD in pediatric RTx was much less ( $20 \%$ ), but no exact figures were available for infant RTx [16]. The use of either of the parents as an LD brings several advantages: timing of the operation is feasible, RTx can be performed pre-emptively, immunological matching is at least satisfactory (one haplotype), the donor age is often low ( $<35$ years), and the cold-ischemia time is very short. On the other hand, the use of a young parent for a kidney donation may raise ethical concerns on the safety of the operation and the long-term health of the donor. It has been shown that living kidney donors maintain long-term renal function and experience no increase in cardiovascular or all-cause mortality. However, in recent surveys, donors showed a slightly increased long-term risk for ESRD and cardiovascular complications [17, 18]. Most genetic kidney diseases manifesting soon after birth show autosomal recessive inheritance and either parent can be used as a donor also in these diseases, such as CNS and ARPKD. If the disorder is not recessively inherited, genetic consultation is important to prevent recurrences after RTx.

The allocation of deceased donor (DD) kidney grafts to children varies worldwide. In the US, the current allocation policy for children (Share35) emphasizes the importance of young donors ( $<35$ years old) and shorter waiting times over HLA-matching [19]. This algorithm has shortened the waiting times but increased mismatches, so that $84 \%$ of transplants to children are mismatched at 4-6 alleles (A,B,DR loci) [20]. A poor match in the first graft also impairs the chances for the second graft, which is important in infant RTx, as these patients inevitably need another graft later in life [21]. In most European centers HLA-A, B, and DR matching is still an important part of organ allocation [19, 22], which may be reflected in the better long-term survival rates in Europe [23]. The great majority of kidney grafts come from brain-death donors, and the experience of donation after cardiac death (DCD) is still limited in pediatric and especially infant RTx [24].

Traditionally, kidneys from young pediatric donors ( $<5$ years of age) have not been used in infant RTx, as the early reports showed a decreased graft survival rate caused by infections and technical problems [25-28]. However, more recent data indicate that a pediatric donor organ can adapt the glomerular filtration rate (GFR) with the recipient's 
growth and these grafts would provide even better long-term results [29, 30]. En bloc kidneys from infant donors have been used for adult recipients and more recently also for older pediatric recipients ( $>4$ years of age), but, to our knowledge, not for infant recipients [31].

ABO-blood group compatibility between the donor and recipient has traditionally been required in RTx. However, $\mathrm{ABO}$-incompatible (ABOi) renal transplantation has become more popular and hundreds of patients have been successfully transplanted across the ABO-barrier [32-34]. Infants have low levels of ABO-antibodies and are immunologically good candidates for ABOi-transplantation. This is evident in heart transplantations, where most ABOi recipients are infants [35]. Thus, it is to be expected that the use of ABOi donors will increase in infant RTx during the coming years.

\section{Timing of transplantation}

Timing of the infant RTx is an important issue. Early transplantation is favored by the fact that transplanted children show better growth, development, and quality of life compared to dialysis patients, and they avoid many complications, such as peritonitis and venous access problems. Both intra- and extraperitoneal placement of the graft can be used (see below) and young infants weighing $<5 \mathrm{~kg}$ have been successfully transplanted $[1,36,37]$. Very early transplantation carries, however, added risks and needs multidisciplinary expertise. Adult-sized grafts have been successfully transplanted into infants weighing $7-10 \mathrm{~kg}$, but a common practice is to perform the operation when a child has reached the weight of 10-20 kg when extraperitoneal placement of the kidney is feasible [36]. This approach was evident in two large international surveys of about 400 infants with ESRD [3, 38]. Besides weight, the child's height, body shape, and size of blood vessels play a role in the planning of the operation. In patients suitable for RTx, long dialysis period does not bring additional value and an early operation is preferred, especially in large specialized transplant centers.

In CNS patients with severe proteinuria, bilateral nephrectomy can be performed at the age of 6-9 months followed by dialysis therapy for some months before an early RTx (weight around $10 \mathrm{~kg}$ ). The other strategy is to perform a unilateral nephrectomy and wait for the development of ESRD. In this case, RTx can be postponed to the age of 2-5 years [39]. According to a recent survey of EDTA-registry data, both approaches seem to result in equally good long-term outcome (T. Hölttä, personal communication, March 20, 2015).

\section{Surgery}

In infant RTx, a kidney graft can be placed intra- or extraperitoneally (Fig. 1 and Table 1). In the former approach, a midline incision is made on the abdominal wall and the graft is placed into the right side of the peritoneal cavity $[1,2]$. After mobilizing the right colon and terminal ileum, the donor renal vein and artery are anastomosed to the recipient vena cava and aorta, respectively, in an end-to-side technique. The donor's ureter is implanted into the recipient's bladder using either a Ledbetter-Politano procedure or one of its modifications. Temporal stenting may be used to reduce the risk of ureteral stenosis, especially when suboptimal arterial blood flow in the distal ureter is suspected. An adult-sized kidney can occupy the entire right side of the abdomen leading to bowel dysfunction and ileus, especially during the early post-operative phase. The lateral edge of the allograft is usually easily accessible to an ultrasound-guided renal biopsy $[1,2,40]$.

When an extraperitoneal placement is used, an incision is made above the right groin (or left side in re-RTx). The peritoneum is mobilized from the anterolateral and posterior abdominal wall, exposing the posterior muscles and the great vessels. The kidney graft artery and vein are usually anastomosed with the common iliac artery and vein, respectively. The sites for anastomoses, however, depend on the relative sizes of the vessels of the graft and the recipient. The greater the size mismatch is, the more proximal recipient vessel anastomoses are used. Still, the available space for an adult-size kidney may present a problem, and to avoid pressure and circulatory problems, it is sometimes safer to close the fascia a few days after the primary operation $[30,41]$. To ensure urine flow, a transvesical catheter is usually placed in the bladder. In infants with CAKUT, there are different intra- and extravesical techniques to make a ureterbladder anastomosis; the choice depends on the anatomy and previous surgery [13].

\section{Peri-and postoperative management}

While intraoperative management of the recipient follows normal anesthetic practice, maintenance of sufficient perfusion of the transplanted kidney is crucial. Sufficient cardiac output and volume overload is needed to ensure adequate perfusion of the allograft. The cardiac output of infants must double in order to perfuse the adult kidney adequately [42]. It is desirable to maintain a central venous pressure above $10 \mathrm{~cm} \mathrm{H}_{2} \mathrm{O}$ prior to unclamping and the mean arterial pressure at more than $60 \mathrm{mmHg}$. Intravenous crystalloid or colloid solutions (Ringersteril, $0.9 \%$ normal saline, $4 \%$ albumin) and mannitol may be used to promote urine output according to the practice of the transplant center.

After the operation, attention to the intravascular volume and electrolyte and acid-base stability is essential to ensure good renal function. During the first days, polyuria is common and urine output can be replaced by $0.45 \%$ (or $0.9 \%$ ) saline solution. Additional fluid infusions may be given if urine output drops. Intravenous furosemide boluses can be given if 
Fig. 1 In infants, the kidney graft can be placed intraperitoneally (a) or extraperitoneally (b)
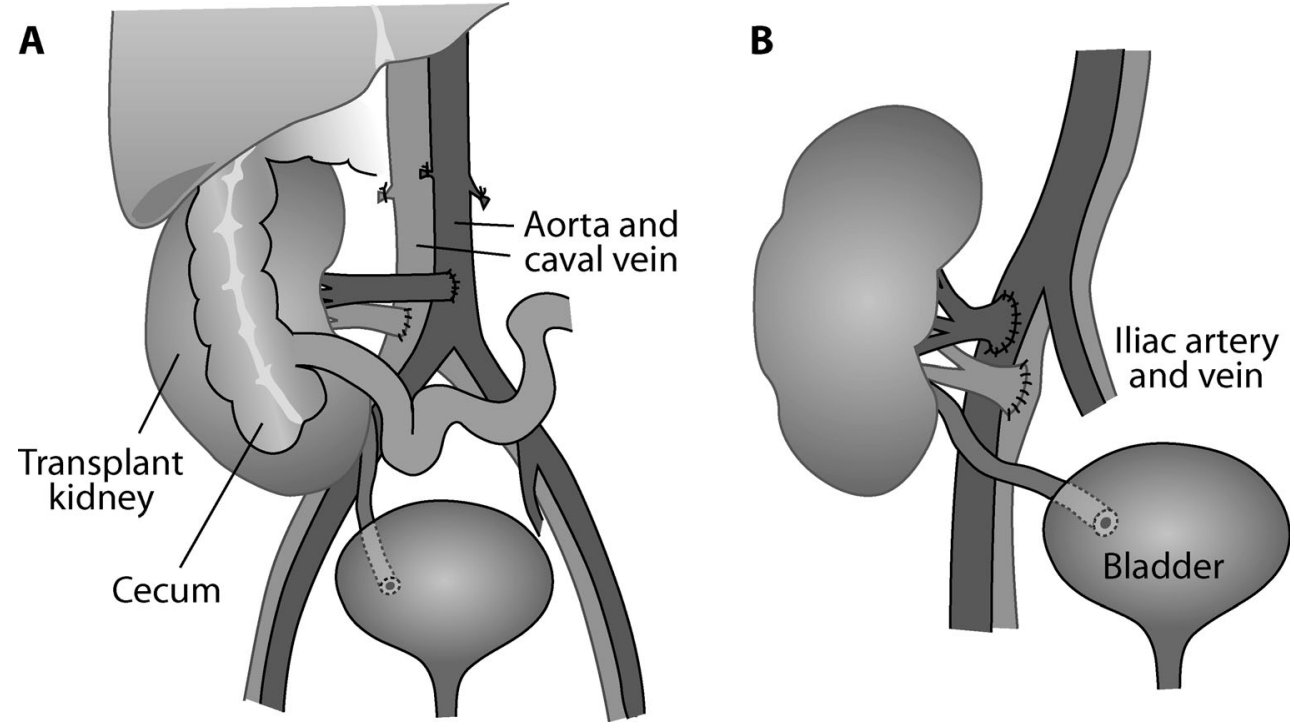

dehydration is excluded. Weight measurements, blood pressure monitoring, and follow-up of fluid input and output are important for securing the safety of excessive fluid administration $\left(2500 \mathrm{ml} / \mathrm{m}^{2}\right)$ [42]. Infant recipients are often slightly oedematous $(0.5-1.0 \mathrm{~kg}$ ) and hypertensive during the first postoperative days. Systolic blood pressure values of 100 $120 \mathrm{mmHg}$ are, however, allowed in this early phase.

Monitoring of serum sodium, potassium, bicarbonate, calcium, phosphorous, and magnesium is essential. Due to variation in the urine output (heavy diuresis, delayed graft function) and use of diuretics and calcineurin inhibitors (CNI), any of these electrolytes may need supplementation. On the other hand, slight hyperkalemia $(5-6 \mathrm{mmol} / \mathrm{l})$ is very common during the first weeks but rarely needs therapy. Oral phosphate and magnesium supplementations may be needed for several months, and calcium-vitamin D supplementation can be given permanently.

Hypertension secondary to high fluid intake, corticosteroids, and CNI is common after RTx. Also, the preoperative blood pressure of both the donor and recipient have an impact on the post-transplantation blood pressure values. Calciumchannel blockers (amlodipine and nifedipine) are widely used in pediatric RTx patients. Antibiotic prophylaxis is given as long as the bladder catheter is kept in situ. Infants without urine output before the operation have a small shrunken urinary bladder, and the catheter is closed for increasing time periods before its final removal. The use of anticoagulation (enoxaparin, ASA) postoperatively is decided individually. Our practice is to start anticoagulation if poor blood flow in the ureter is suspected or a small pediatric graft is used. Prophylaxis against Pneumocystis jirovecii (co-trimazole) and cytomegalovirus (CMV) (ganciclovir/valganciclovir) are routinely used by most centers for 3-12 months after the operation. Infants are often CMV negative at the time of RTx and receive a CMV positive graft from an adult donor and, thus, have a clear risk for CMV infection.
Immunosuppressive medication protocols are center-specific. This is so for both perioperative induction therapy and maintenance medication. In the NAPRTCS report from 2010, no induction was used in $54 \%$, antithymocyte globulin (ATG) in $27 \%$, and basiliximab (anti-IL2-receptor antibody) in $10 \%$ of the US centers [5]. Triple medication with CNI (tacrolimus or cyclosporine A (CsA)), antimetabolite (mycophenolate mofetil (MMF) or azathioprine) and glucocorticoid (prednisone or methylprednisolone) is typically used as an early maintenance medication. According to the NAPRTCS report, immunosuppression at 30 days after RTx included prednisone in $50 \%$, tacrolimus in $60 \%$, MMF in $60 \%$, and CsA and azathioprine in only a small percentage in the US centers [5].

In general, infants need the same medication as older pediatric RTx patients. In our center, the early immunosuppressive protocol is still CsA-based, as the dosing in the smallest recipients is easier and more accurate with CsA as compared to tacrolimus. Due to the faster metabolic capacity of smaller children, CsA is at first given to the infants three times a day [43]. Steroid-free protocols are successfully used in many transplant centers to avoid the side effects of glucocorticoids

Table 1 Important short-term issues in infant renal transplantation

Choice of intra- vs. extraperitoneal placement of the graft

Abundant fluid administration intra- and postoperatively

Monitoring and supplementation of electrolytes ( $\mathrm{Na}, \mathrm{K}, \mathrm{Mg}, \mathrm{Pi}, \mathrm{HCO}_{3}$ )

Regular weight and blood pressure measurements

Ultrasound monitoring for blood circulation, pelvic/ureteral diameters, perinephric fluid collections

Core needle biopsy if an acute rejection is suspected

Monitoring of CNI-levels

Infection surveillance and prophylaxis

CNI calcineurin inhibitors 
[44]. The other possibility is to switch to low-dose $(0.1 \mathrm{mg} / \mathrm{kg} /$ day), every-other-day medication, which also effectively abolishes the steroid side effects $[45,46]$.

\section{Surgical complications}

The most common cause of early graft failure in young recipients is graft thrombosis. In the original reports on infant RTx, frequencies up to $30 \%$ were reported, but recently the incidence of thrombosis has been $2-10 \%$ in infants $[47,48]$. The smaller size of the blood vessels predisposes infants to thrombotic events, and investigation of the size of blood vessels in the recipient before RTx is recommended. Also, perfusion and preimplantation damage, long ischemia time, hypotension and hypoperfusion of the graft, as well as immune mechanisms have been associated with the development of thrombosis [47].

Venous thrombosis leads to instant swelling of the graft and is easily clinically diagnosed. The diagnosis of arterial thrombosis is made by ultrasound (US). Arterial and venous thromboses often result in graft loss. Thus, it is essential to evaluate perfusion of renal vessels by US immediately after operation and on a daily basis thereafter. The US demonstrates alterations in renal hemodynamics such as reduction, absence or reversal of diastolic flow, which is seen as a change in the resistance index (RI). RI changes can be caused by parenchymal edema (rejection), external compression of vasculature structures, or venous kinking. When an adult-sized kidney is transplanted into an infant, the RI values are often higher than with older children [49]. Marked changes in the RI value, not the baseline, are important.

The postoperative US monitoring may reveal peritransplant fluid collection, such as a seroma, blood clot, urinoma, or lymphocele. The first two do not usually cause urinary obstruction and seldom need intervention. On the other hand, urinoma and lymphocele located between the kidney graft and urinary bladder may cause ureteral stenosis and obstruction leading to a dilatation of the ureter and hydronephrosis of the graft. These require surgical drainage and in some cases laparoscopic fenestration of the lymphocele into the peritoneal cavity is needed.

Disintegration of the distal ureter or rupture of the bladder can cause a urine leak. If urinary extravasation is diagnosed, exploration and correction of the underlying problem is indicated. Kinking of the ureter or blockage at the implantation site of the ureter may need temporary ureteral stenting to ensure adequate urine flow. Fibrosis of the distal ureter following ischemia resulting from compromised ureteral arterial flow may lead to gradual stenosis or obstruction of the ureter. Temporary management includes placement of a percutaneous nephrostomy or ureteral stent. Operative management includes ureterocystostomy and uretero- or pyeloureterostomy using the native ureter.

\section{Acute rejection}

Improvements in immunosuppressive medication have resulted in a remarkable decrease in the incidence of acute rejection (AR) in pediatric RTx patients. In the latest NAPRTCSregistry (years 2007-2010), the probability of AR during the first 12 months had decreased to 8.6 and $16.6 \%$ in LD and DD transplantations, respectively [5]. An interesting question is whether infants have a different risk for rejection as compared to older children. Previously, heightened immunoactivity was suggested. However, in the recent registry data, infants showed relative hazard rates of 0.51 and 0.89 for the first $\mathrm{AR}$ in LD and DD transplantations, respectively, indicating that the risk was moderately decreased. In our experience, infants are not very different from older children in developing AR. A renal biopsy is mandatory for a diagnosis of AR in infants, since a large adult-sized kidney can undergo substantial damage before a rise in serum creatinine occurs $[50,51]$.

The literature on acute antibody-mediated rejection in pediatric and especially infant RTx is still scarce. It is to be expected that preformed HLA-antibodies are less common in infants than in older children. De novo donor-specific antibodies (DSA) can be detected also in pediatric patients and they have been associated with decreased long-term graft function $[52,53]$. However, contradictory results on the importance of DSA have been published [54].

\section{Infections}

Peri- or postoperative bacterial or yeast infections are not common in infant RTx recipients. Urinary tract infections (UTI) are, however, quite frequent and associated with vesicoureteral reflux to the graft and sometimes to native kidneys. In the study of Their et al., the frequency of UTI in RTx children $<2$ years and 2-5 years of age was 0.3 and 0.1 episodes/patient year, respectively, suggesting that infants are not especially prone to UTI [55]. Increased occurrence of UTI has been reported in RTx patients with CAKUT and bladder dysfunction [14]. In recent reports, the UTI frequency in patients with diverted or augmented bladder was, however, not exceptionally high [13, 56]. Management of UTI is important, as repeat episodes may hasten deterioration of graft function and with some infants it is wise to use antibiotic prophylaxis.

Viral respiratory tract infections (URI) are by far the most frequent infectious complication of RTx infants. In our experience, complicated respiratory infections among RTx recipients are, however, rare, and even small children recover from URI quite normally; hospitalization of a patient due to URI is rarely needed [55]. As is the case in the general population, gastrointestinal infections are not rare among small transplant children [55]. Diarrhea and vomiting may require intravenous fluid therapy and medication as well as intensified drug 
monitoring. Even a moderate dehydration often leads to temporally increased creatinine levels in RTx infants.

CMV, Epstein-Barr virus (EBV), and Polyomaviruses (PV) (nephritis caused by BK virus and less often JC virus) are a major concern in pediatric RTx patients of all ages. Since most infants are seronegative for these viruses at the time of transplantation, primary infection after RTx is common. Monitoring of these viruses by a PCR method from blood or plasma samples is highly recommended [57]. CMV viremia is rare in patients receiving valganciclovir prophylaxis, but after stopping the medication, subclinical or clinical viremia is quite common.

Management of PV and EBV viremias is more complicated, as the there is no effective therapy for either virus, with the exception of reduction of the immunosuppressive medication. In the case of PV infection, nephritis caused by this virus can be verified by kidney biopsy, which should be taken when significant viremia $(>10,000$ copies $/ \mathrm{ml})$ or signs of renal graft dysfunction are noticed. Constant EBV viremia may lead to the development of post-transplant lymphoproliferative disease (PTLD) and increasing EBV DNA levels usually require reduction of immunosuppressive medication, which increases the risk of rejection [58]. In a recent survey, the relative hazard for PTLD was 5.3-fold higher in children aged $<6$ years of age versus those $>12$ years, and EBV seronegative subjects had a 4.7 -fold higher risk compared to EBV-positive subjects [58]. In our center, PTLD has been diagnosed in seven of the 252 RTx patients $(3.7 \%)$ and four of these had received their kidney graft as infants. Excellent articles on the management of CMV, EBV, and PV infections have recently been published [57-61].

\section{Long-term problems}

While the short-term results of infant RTx are nowadays excellent, the major issue is how these children manage in the long run (Table 2). Patients who received RTx at young age need follow-up and therapy for several decades, not several years. Important issues are long-term graft function, growth, pubertal maturation and fertility, bone health, metabolic problems, neurocognitive development, adherence to medication, and quality of life.

\section{Graft function}

The most important cause of late graft failure is chronic renal allograft injury that accounts for one-third of the graft losses in pediatric RTx patients [5, 62]. The term includes chronic active T-cell-mediated and antibody-mediated rejections, arteriopathy and interstitial fibrosis/tubular atrophy with no specific etiology $[63,64]$. According to our experience, chronic allograft injury is detected to a similar extent in the allografts of patients who received their transplant in infancy or later in childhood [65]. This is reflected in the similar pattern of GFR deterioration with
Table 2 Important long-term issues in infant renal transplantation

Graft function

Viral surveillance

HLA-antibody surveillance

Growth

Motor development

Neurocognitive development

Cosmetic side effects of the medication

Bone health

Metabolic risk factors

Life quality

Pubertal development

Adherence to medication

Programmed transition to an adult unit

HLA human leukocyte antigen

time, as shown in Fig. 2. The mean annual decline of measured GFR is $2.2 \mathrm{ml} / \mathrm{min} / 1.73 \mathrm{~m}^{2}$, indicating that infant RTx recipients need a new graft as young adults.

\section{Growth}

Most infants are growth-deficient at the time of RTx. The NAPRTCS registry data showed that the youngest recipients (1-2 years) had a negative height $Z$ score (hSDS) of -2.2 at the time of transplantation, but exhibited substantial catch-up growth (up to $-1.4 \mathrm{SD}$ ) for the initial 3-4 years after transplantation before plateauing and subsequently exhibiting a decline in the height score (-1.7 SD at 6 years) [66]. In the study by Qvist et al., children $<2$ years of age had a mean hSDS of 1.1 both at RTx and 7 years after the operation [67]. Growth after $\mathrm{RTx}$ is satisfactory, but the final height attained by most recipients is not their calculated target height $[68,69]$. The results

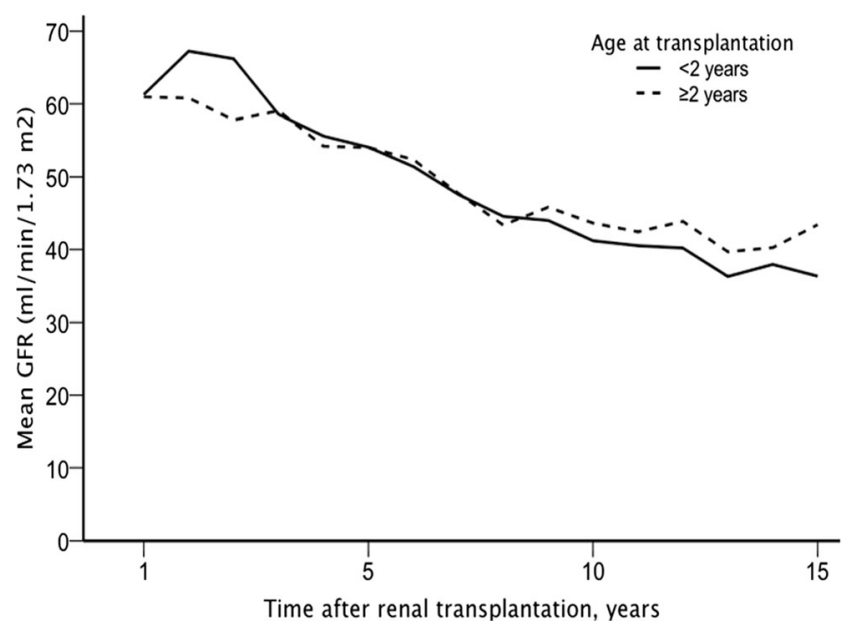

Fig. 2 Measured annual glomerular filtration rate (GFR) in 61 patients transplanted before the age of 24 months and in 127 patients transplanted after the age of 24 months (Children's Hospital, Helsinki) 
emphasize the importance of the preoperative management of infants with ESRD or nephrosis [70]. After RTx, allograft function and steroid exposure have an impact on growth, and in those with poor growth, steroid dosing should be minimized. Especially in adolescence, short stature can have major consequences on quality of life and self-esteem.

For the most stunted patients, recombinant growth hormone $(\mathrm{GH})$ therapy has been used for over 20 years, and the therapy has been effective in inducing substantial catch-up growth in most patients. There have, however, been some concerns that the therapy might induce rejections or PTLD. A recent meta-analysis confirmed that $\mathrm{GH}$ therapy promotes growth velocity in RTx children [71]. In this analysis, the risk for rejection was slightly increased (risk ratio 1.56) in patients receiving GH. On the other hand, a report from Australia and New Zealand did not find a relationship between GH use and PTLD [72]. Monitoring of growth for at least 1 year posttransplantation is recommended before starting (or restarting) GH therapy. One practical problem with GH therapy is that it is expensive, and must be continued for years, as the positive effect stops when the therapy is discontinued.

\section{Pubertal development}

Besides growth, pubertal developmental and fertility are important long-term issues in adolescents and adults who were transplanted as infants. Delayed puberty has been reported in several studies on pediatric RTx patients [73, 74]. In a recent report by Tainio et al., children who underwent RTx at a young age (most patients $<2$ years at RTx) had quite normal puberty and reached it earlier than those transplanted at later age (12.3 vs. 13.4 years) [69]. Twenty percent of boys and none of the girls had a delayed onset of puberty. The bone age was delayed in practically all and final height was achieved at 18.1 and 16.0 years in boys and girls, respectively, which provides growth potential for a longer time. In a subsequent study, the reproductive endocrine function of adult men who received RTx as small children was, however, impaired. Despite quite normal sex hormone levels, only one-fifth of these young men had normal sperm counts [75]. Studies on the fertility of young women transplanted in early childhood are still required.

\section{Bone health}

Mineral and bone disorder in RTx children may result in decreased bone mineral density (BMD), fractures, bone pain, and growth failure [76, 77]. In a cross-sectional study by Valta et al., vertebral fractures were observed in $8 \%$ of RTx children (median age 12 years) and the majority of them were asymptomatic. The height-adjusted BMD in lumbar spine was satisfactory and similar in patients transplanted before the age of 2 years as compared to those transplanted at a later age $(-0.5$
SD vs. -0.4 SD) [78]. Female sex and age $>15$ years as well as high PTH levels were significant predictors of low BMD. As the basis for lifelong bone health is established in childhood and adolescence, follow-up measurement of bone mineralization by DXA and spinal imaging of vertebral fractures is warranted [79]. Therapeutic efforts to reduce MBD include vitamin D, calcium, and sometimes phosphate supplementation.

\section{Metabolic risk factors}

In children transplanted at a very young age, avoidance of metabolic risk factors such as obesity, hypertension, dyslipidemia, and impaired glucose metabolism, is important in two respects. First, these factors may adversely affect the graft function and, secondly, they may lead to early cardiovascular problems that can impair later therapies (retransplantation in adulthood). The data on metabolic risk factors among pediatric RTx patients are still limited. In a cohort of patients mostly transplanted before the age of 2 years, metabolic syndrome, overweight, hypertension, and type 2 diabetes were observed in $14-19 \%, 20-23 \%, 61-87 \%$, and $3-5 \%$ of patients at $1.5-$ 5 years after RTx, respectively [45]. Higher incidences of these risk factors, however, have been reported in pediatric RTx patients [80-83]. Thus, the follow-up of blood pressure is crucial and antihypertensive medication is required in the majority of the patients. In addition, significant proteinuria is associated with worse outcome and should be taken into account in the medication [84].

\section{Neurocognitive development}

Children with renal failure from infancy would be expected to have a less favorable neurodevelopmental prognosis. This is especially so in patients with neurological comorbidities and those who suffered from thrombotic events before RTx. However, in many children, the neuromotor development after RTx is satisfactory. In a recent report, patients (mean age, 11 years) diagnosed with ESRD as infants had intellectual and metacognitive functioning significantly lower than sibling controls with the mean Full Scale IQ scores of 78 and 94, respectively [85]. In a report of 33 school-aged children transplanted before the age of 5 years, younger age at RTx was associated with higher scores on several parameters. The mean intelligent quotient (IQ) was 87, and 6-24\% showed impairment in neuropsychological tests. About $80 \%$ of the children attended normal school and $76 \%$ had normal motor performance [86]. In another study, 50 children transplanted at an early age were assessed at a mean age of 11.1 years. The RTx group scored generally lower than the control group on neuropsychological assessment. The difference was evident in both the verbal and visuospatial domains and verbal working memory. A better cognitive outcome was associated with the 
absence of neurological co-morbidity, younger age, shorter disease duration, and sustained kidney function [87].

\section{Life quality}

The ultimate goal of RTx is to provide a good overall wellbeing of the patients. In general, the psychosocial outcome after RTx children is satisfactory, so that most patients and their parents have a good life according to themselves [88]. In a study of psychosocial adjustment in school-aged children, most of whom had received an RTx during infancy, the healthrelated measure was comparable to normal school children [89]. The reported results have, however, been variable, and in a quite recent study, RTx children (aged 3-19 years) showed higher levels of mental health problems and lower quality of life as compared to controls [90]. Quality of life has also been studied in young adults who received RTx in childhood. Again, the results are varied, but most patients are quite satisfied with their life [91-93]. Adolescents who received RTx in infancy, and do not remember the "hard times" before and after RTx, need thorough surveillance for adherence to medication and help in transition to an adult unit.

Comorbidities significantly affect quality of life and many disabilities originate from the time before RTx [94]. Although the quality of life is not necessarily correlated to the degree of physical disability, much effort should be made to diminish the complications, which have an impact for later adjustment. Continuous multidisciplinary support, follow-up, and education are needed to cope with this problem.

\section{Key summary points}

- In infants, congenital anomalies of the kidneys and urinary tract (CAKUT) and congenital nephrotic syndrome are the most common causes of renal transplantation. Active treatment of an infant with renal failure is important to ensure optimal postoperative outcome.

- Renal transplantation with intraperitoneal engraftment can be performed on an infant weighing 6-10 kg. If the graft is placed extraperitoneally, transplantation is usually performed when the child has reached the weight of 10 $15 \mathrm{~kg}$. Intra- and perioperative management of a recipient is focused on maintenance of sufficient perfusion of the transplanted kidney and avoidance of thrombosis, rejections, and infections.

- Infants need life-long immunosuppressive medication, including calcineurin inhibitor, antimetabolite, and corticosteroid. Management of the many side effects of these drugs is important to ensure good growth and development.

\section{Conclusions}

The overall outcome of infant RTx has dramatically improved such that several registry data and single-center reports show 10 -year patient and graft survivals of over 90 and $80 \%$, respectively [95]. Short-term problems after transplantation are more common in infants than in older children [5], but the long-term outcome figures in infants are better, with a relative hazard for graft failure being about $0.2-0.6$ in infants as compared to adolescents [96]. Infants receiving living donor grafts have estimated graft half-life of almost 30 years [96]. Careful follow-up of subjects who received kidney grafts as small children is needed to ensure optimal growth and development, as well as good quality of life in adulthood when the second kidney transplantation is required.

\section{Multiple-choice questions (answers are supplied following the reference list)}

1) Infants form a special group of pediatric renal transplant recipients. Of all pediatric recipients they account for:
a. $<10 \%$
b. $10-19 \%$
c. $20-29 \%$
d. $30-39 \%$
e. $>40 \%$

2) Acute rejections are nowadays diagnosed less often than before. Their frequency in infant renal transplantation is:
a. $40-60 \%$
b. $30-39 \%$
c. $20-29 \%$
d. $5-19 \%$
e. $<5 \%$

3) Infant kidney transplant recipients are often seronegative for Epstein-Barr virus (EBV) at the time of transplantation. The risk for post-transplant lymphoproliferative disorder (PTLD) in seronegative recipients, as compared to seropositive subjects, is:
a. 2-fold
b. 5-fold
c. 8-fold
d. 10-fold
e. 20-fold

4) In infant renal transplantation the major cause of early graft loss is:
a. acute rejection
b. unrinary tract infection
c. ureteral stenosis 

d. lymphocele
e. vascular thrombosis

5) The overall outcome of renal transplantation in infants is nowadays good. Graft survival ten years after the operation is:
a. $50 \%$
b. $60 \%$
c. $70 \%$
d. $80 \%$
e. $99 \%$

Conflict of interest The authors declare that they have no conflict of interest.

\section{References}

1. Najarian JS, Simmons RL, Tallent MB, Kiellstrand CM, Buselmeier TJ, Vernier RL, Michael AF (1971) Renal transplantation in infants and children. Ann Surg 174:583-600

2. Chavers B, Najarian JS, Humar A (2007) Kidney transplantation in infants and small children. Pediatr Transplant 11:702-708

3. van Stralen KJ, Borzych-Duzalka D, Hataya H, Kennedy SE, Jager KJ, Verrina E, Inward C, Rönnholm K, Vondrak K, Warady BA, Zurowska AM, Schaefer F, Cochat P, ESPN/ERA-EDTA registry; IPPN registry; ANZDATA registry; Japanese RRT registry (2014) Survival and clinical outcomes of children starting renal replacement therapy in the neonatal period. Kidney Int 86:468-174

4. Pruthi R, O'Brien C, Casula A, Braddon F, Lewis M, Maxwell H, Tse Y, Inward C, Sinha MD (2013) UK Renal registry 15th annual report: chapter 4 demography of the UK paediatric renal replacement therapy population in 2011. Nephron Clin Pract 123:81-92

5. Smith JM, Martz K, Blydt-Hansen TD (2013) Pediatric kidney transplant practice patterns and outcome benchmarks, 1987-2010: a report of the North American pediatric renal trials and collaborative studies. Pediatr Transplant 17:149-157

6. Rees L (2008) Management of the neonate with chronic renal failure. Semin Fetal Neonatal Med 13:181-188

7. Wühl E, van Stralen KJ, Verrina E, Bjerre A, Wanner C, Heaf JG, Zurriaga O, Hoitsma A, Niaudet P, Palsson R, Ravani P, Jager KJ, Schaefer F (2013) Timing of renal replacement therapy in patients with congenital malformations of the kidney and urinary tract. Clin J Am Soc Nephrol 8:67-74

8. Warady BA, Neu A, Schaefer F (2014) Optimal care of the infant, child, and adolescent on dialysis: 2014 update. Am J Kidney Dis 64:128-142

9. Watson AR, Hayes WN, Vondrak K, Ariceta G, Schmitt CP, Ekim M, Fischbach M, Edefonti A, Shroff R, Holta T, Zurowska A, Klaus G, Bakkaloglu S, Stefanidis CJ, Van de Walle J, European Paediatric Dialysis Working Group (2013) Factors influencing choice of renal replacement therapy in European pediatric nephrology units. Pediatr Nephrol 28:2361-2368

10. Querfeld U, Stefanidis CJ (2012) Pediatrics: when should children surviving a Wilms tumor be transplanted? Nat Rev Nephrol 8:443-444

11. Khositseth S, Askiti V, Nevins TE, Matas AJ, Ingulli EG, Najarian JS, Gillingham KJ, Chavers BM (2007) Increased urologic complications in children after kidney transplants for obstructive and reflux uropathy. Am J Transplant 7:2152-2157
12. González-Jorge AL, Hernández-Plata JA, Bracho-Blanchet E, RayaRivera AM, Romero-Navarro B, Reyes-López A, Varela-Fascinetto G (2010) Should a complex uropathy be a contraindication for renal transplantation in children? Transplant Proc 42:2365-2368

13. Christman MS, Canning DA, Schast AP, Baluarte HJ, Kaplan BS (2013) Renal transplantation into a diverted urinary system-is it safe in children? J Urol 190:678-682

14. Lopez Pereira P, Ortiz Rodriguez R, Fernandez Camblor C, Martínez Urrutia MJ, Lobato Romera R, Espinosa L, Jaureguizar Monereo E (2013) Renal transplant outcome in children with augmented bladder. Front Pediatr 1:42

15. Goldberg AM, Amaral S, Moudgil A (2014) Developing a framework for evaluating kidney transplant candidacy in children with multiple comorbidities. Pediatr Nephrol 30:5-13

16. Cransberg K, Smits JM, Offner G, Nauta J, Persijn GG (2006) Kidney transplantation without prior dialysis in children: the Eurotransplant experience. Am J Transplant 6:1858-1864

17. Muzaale AD, Massie AB, Wang MC, Montgomery RA, McBride MA, Wairight JL, Segev DL (2014) Risk of end-stage renal disease following live kidney donation. JAMA 311:579-586

18. Mjøen G, Hallan S, Hartmann A, Foss A, Midtvedt K, Øyen O, Reisæter A, Pfeffer P, Jenssen T, Leivestad T, Line PD, Øvrehus M, Dale DO, Pihlstrøm H, Holme I, Dekker FW, Holdaas H (2014) Long-term risks for kidney donors. Kidney Int 86:162-167

19. Foster BJ, Dahhou M, Zhang X, Platt RW, Hanley JA (2013) Relative importance of HLA mismatch and donor age to graft survival in young kidney transplant recipients. Transplantation 96: 469-475

20. Amaral S, Patzer RE, Kutner N, McClellan W (2012) Racial disparities in access to pediatric kidney transplantation since share 35 . J Am Soc Nephrol 23:1069-1077

21. Foster BJ, Dahhou M, Zhang X, Platt RW, Smith JM, Hanley JA (2014) Impact of HLA mismatch at first kidney transplant on lifetime with graft function in young recipients. Am J Transplant 14:876-885

22. Persijn GG (2006) Allocation of organs, particularly kidneys, within Eurotransplant. Hum Immunol 67:419-426

23. Gondos A, Döhler B, Brenner H, Opelz G (2013) Kidney graft survival in Europe and the United States: strikingly different longterm outcomes. Transplantation 95:267-274

24. Yoo P, Olthoff KM, Abt PL (2011) Donation after cardiac death in pediatric organ transplantation. Curr Opin Organ Transplant 16: 483-488

25. Talbot D, Achilles OA, Mirza D, Buckels J, Mayer AD, Milford DV (1998) Early risk factors in pediatric renal transplantation at a single center. J Pediatr Surg 33:1396-1398

26. Johnson RJ, Armstrong S, Belger MA, Fuggle SV, Martin S, Middleton D, Ray TC, Rigden SP, Verrier-Jones K, Morris PJ, Paediatric Task Force of United Kingdom Transplant, Bristol, UK (2002) The outcome of pediatric cadaveric renal transplantation in the UK and Eire. Pediatr Transplant 6:367-377

27. Mitsnefes M, Stablein D (2005) Hypertension in pediatric patients on long-term dialysis: a report of the North American Pediatric Renal Transplant Cooperative Study (NAPRTCS). Am J Kidney Dis 45:309-315

28. Sarwal MM, Cecka JM, Millan MT, Salvatierra O Jr (2000) Adultsize kidneys without acute tubular necrosis provide exceedingly superior long-term graft outcomes for infants and small children. Transplantation 70:1728-1736

29. Dubourg L, Cochat P, Hadj-Aïssa A, Tydén G, Berg UB (2002) Better long-term functional adaptation to the child's size with pediatric compared to adult kidney donors. Kidney Int 62: $1454-1460$

30. Becker T, Neipp M, Reichart B, Pape L, Ehrtich J, Klempnauer J, Offner G (2006) Paediatric kidney transplantation in small children - a single-centre experience. Transplant Int 19:197-202 
31. Zhao WY, Zhang L, Zhu YH, Chen Y, Zhu FY, Shen Q, Xu H, Zeng L (2014) En bloc kidneys transplanted from infant donors less than $5 \mathrm{~kg}$ into pediatric recipients. Transplantation 97:555-558

32. Opelz G, Morath C, Süsal C, Tran TH, Zeler M, Döhler B (2015) Three-year outcomes following 1,420 ABO-incompatible living donor kidney transplants performed after $\mathrm{ABO}$ antibody reduction: results from 101 centers. Transplantation 99:400-404

33. Murmatsu M, Gonzalez HD, Cacciola R, Aikawa A, Yaqoob MM, Puliatti C (2014) ABO incompatible renal transplants: good or bad? World J Transplant 4:18-29

34. Tydén G, Kumlien G, Berg UB (2011) ABO-incompatible kidney transplantation in children. Pediatr Transplant 15:502-504

35. Urschel S, Larsen IM, Kirk R, Flett J, Burch M, Shaw N, Birnbaum J, Netz H, Pahl E, Matthews KL, Chinnock R, Johnston JK, Derkatz $\mathrm{K}$, West LJ (2013) ABO-incompatible heart transplantation in early childhood: an international multicentre study of clinical experiences and limits. J Heart Lung Transplant 32:285-292

36. Salvatierra O Jr, Millan M, Concepcion W (2006) Pediatric renal transplantation with considerations for successful outcome. Semin Pediatr Surg 15:208-217

37. Englund M, Berg U, Tydén G (2003) A longitudinal study of children who received renal transplants 10-20 years ago. Transplantation 76:311-318

38. Carey WA, Talley LI, Sehring SA, Jaskula JM, Mathias RS (2007) Outcomes of dialysis initiated during the neonatal period for treatment of end-stage renal disease: a North American pediatric renal trials and collaborative studies special analysis. Pediatrics 119: e468-e473

39. Coulthard MG, Crosier J (2002) Outcome of reaching end stage renal failure in children under 2 years of age. Arch Dis Child 87: 511-517

40. Neipp M, Offner G, Lück R, Latta K, Strehlau J, Schlitt HJ, Ehrich JH, Klempnauer J, Br N (2002) Kidney transplantation in children weighing less than $15 \mathrm{~kg}$ : donor selection and technical considerations. Transplantation 73:409-416

41. Vitola SP, Gnatta D, Garcia VD, Garcia CD, Bittencourt VB, Keitel E, Pires FS, D'Avila AR, Silva JG, Amaral RL, Santos LN, Kruel CD (2013) Kidney transplantation in children weighing less than 15 $\mathrm{kg}$ : extraperitoneal access-experience with 62 cases. Pediatr Transplant 17:445-453

42. Salvatierra O Jr, Singh T, Shifrin R, Conley S, Alexander S, Tanney D, Lemley K, Sarwal M, Mackle F, Elfrey E, Orlandi P, Zarins C, Herfkens R (1998) Successful transplantation of adult-sized kidneys into infants requires maintenance of high aortic blood flow. Transplantation 66:819-823

43. Fanta S, Backman JT, Seikku P, Holmberg C, Hoppu K (2005) Cyclosporine A monitoring - how to account for twice and three times daily dosing. Pediatr Nephrol 20:591-596

44. Li L, Chang A, Naesens M, Kambham N, Waskewitz J, Martin J, Wong C, Alexander S, Grimm P, Concepcion W, Salvatierra O, Sarwall MM (2009) Steroid-free immunosuppression since 1999: 129 pediatric renal transplants with sustained graft and patient benefits. Am J Transplant 9:1362-1372

45. Tainio J, Qvist E, Hölttä T, Pakarinen M, Jahnukainen T, Jalanko H (2014) Metabolic risk factors and long-term function after pediatric renal transplantation. Transplant Int 27:583-592

46. Seikku P, Raivio T, Jänne OA, Neuvonen PJ, Holmberg C (2006) Methylprednisolone exposure in pediatric renal transplant patients. Am J Transplant 6:1451-1458

47. Smith JM, Stablein DM, Munoz R, Hebert D, McDonald RA (2007) Contributions of the transplant registry: the 2006 annual report of the North American pediatric renal trials and collaborative studies (NAPRTCS). Pediatr Transplant 11:366-373

48. McDonald RA, Smith JM, Stablein D, Harmon WE (2003) Pretransplant peritoneal dialysis and graft thrombosis following pediatric kidney transplantation: a NAPRTCS report. Pediatr Transplant 7:204-208

49. Gholami S, Sarwal MM, Naesens M, Ringertz HG, Barth RA, Balise RR, Salvatierra O (2010) Standardizing resistive indices in healthy pediatric transplant recipients of adult-sized kidneys. Pediatr Transplant 14:126-131

50. Qvist E, Their M, Krogerus L, Holmberg C, Jalanko H (2007) Early treatment of acute rejections gives favorable long-term function after renal transplantation in small children. Pediatr Transplant 11: 895-900

51. Their M, von Willebrand E, Taskinen E, Rönnholm K, Holmberg C, Jalanko H (2001) Fine-needle aspiration biopsy allows early detection of acute rejection in children after renal transplantation. Transplantation 71:736-743

52. Ginevri F, Nocera A, Comoli P, Innocente A, Cioni M, Parodi A, Fontana I, Magnasco A, Nocco A, Tagliamacco A, Sementa A, Ceriolo P, Ghio L, Zecca M, Cardillo M, Gariboto G, Ghiggeri GM, Poli F (2012) Posttransplant de novo donorspecific hla antibodies identify pediatric kidney recipients at risk for late antibody-mediated rejection. Am J Transplant 12: $3355-3362$

53. Kim JJ, Balasubramanian R, Michaelides G, Wittenhagen P, Sebire NJ, Mamode N, Shaw O, Vaughan R, Marks SD (2014) The clinical spectrum of de novo donor-specific antibodies in pediatric renal transplant recipients. Am J Transplant 14:2350-2358

54. Miettinen J, Peräsaari J, Lauronen J, Qvist E, Valta H, Pakarinen M, Merenmies J, Jalanko H (2012) Donor-specific HLA-antibodies and graft function after renal transplantation. Pediatr Nephrol 27: 1011-1019

55. Their M, Holmberg C, Lautenschlager I, Höckerstedt K, Jalanko H (2000) Infections in pediatric kidney and liver transplant patients after perioperative hospitalization. Transplantation 69:1617-1623

56. Pereira PL, Urrutia MJ, Lobato R, Jaureguizar R (2014) Renal transplantation in augmented bladders. Curr Urol Rep 5:431-433

57. Comoli P, Ginevri F (2012) Monitoring and managing viral infections in pediatric transplant recipients. Pediatr Nephrol 27:705-717

58. McDonald RA, Smith JM, Ho M, Lindblad R, Ikle D, Grimm P, Wyatt R, Arar M, Liereman D, Gridges N, Harmon W, CCTPT Study Group (2008) Incidence of PTLD in pediatric renal transplant recipients receiving basiliximab, calcineurin inhibitor, sirolimus and steroids. Am J Transplant 8:984-949

59. Smith JM, Dhamidharka VR, Talley L, Martz K, McDonald RA (2007) BK virus nephropathy in pediatric renal transplant recipients: an analysis of the North American pediatric renal trials and collaborative studies (NAPRTCS) registry. Clin J Am Soc Nephrol 2:1037-1042

60. Smith JM, Dharnidharka VR (2015) Viral surveillance and subclinical viral infection in pediatric kidney transplantation. Pediatr Nephrol 30:741-748

61. Höcker B, Fickenscher H, Delecluse HJ, Böhm S, Küsters U, Schnitzler P, Pohl M, John U, Kemper MJ, Fehrenbach H, Wigger M, Holder M, Schröder M, Billing H, Fichtner A, Feneberg R, Sander A, Köpf-Shakib S, Süsal C, Tönshoff B (2013) Epidemiology and morbidity of Epstein-Barr virus infection in pediatric renal transplant recipients; a multicenter, prospective study. Clin Infect Dis 56:84-92

62. Tejani A, Ho PL, Emmett L, Stablein DM, North American Pediatric Renal Transplant Cooperative Study (NAPRTCS) (2002) Reduction in acute rejections decreases chronic rejection graft failure in children: a report of the North American Pediatric Renal Transplant Cooperative Study (NAPRTCS). Am J Transplant 2:142-147

63. Haas M (2014) An updated Banff schema for diagnosis of antibody-mediated rejection in renal allografts. Curr Opin Organ Transplant 19:315-322 
64. Dart AB, Schall A, Gibson IW, Blydt-Hansen TD, Birk PE (2010) Patterns of chronic injury in pediatric renal allografts. Transplantation 89:334-340

65. Miettinen J, Helin H, Pakarinen M, Jalanko H, Lauronen J (2014) Histopathology and biomarkers in prediction of renal function in children after kidney transplantation. Transplant Immunol 31:105-111

66. Fine RN, Martz K, Stablein D (2010) What have 20 years of data from the North American Pediatric Renal Transplant Cooperative Study taught us about growth following renal transplantation in infants, children, and adolescence with renal end-stage renal disease? Pediatr Nephrol 25:739-746

67. Qvist E, Marttinen E, Rönnholm K, Antikainen M, Jalanko H, Sipilä I, Holmberg C (2002) Growth after renal transplantation in infancy or early childhood. Pediatr Nephrol 17:438-443

68. Harambat J, Cochat P (2009) Growth after renal transplantation. Pediatr Nephrol 24:1297-1306

69. Tainio J, Qvist E, Vehmas R, Jahnukainen K, Hölttä T, Valta H, Jahnukainen T, Jalanko H (2011) Pubertal development is normal in adolescents after renal transplantation in childhood. Transplantation 92:404-409

70. Franke D, Winkel S, Gellerman J, Querfeld U, Pape L, Ehrich JH, Haffner D, Pavičić L, Zivičnjak M (2013) Growth and maturation improvement in children on renal replacement therapy over the past 20 years. Pediatr Nephrol 28:2042-2051

71. Wy Y, Cheng W, Yang XD, Xiang B (2013) Growth hormone improves growth in pediatric renal transplant recipients - a systematic review and meta-analysis of randomized controlled trials. Pediatr Nephrol 28:129-133

72. Longmore DK, Conwell LS, Burke JR, McDonald SP, McTaggart SJ (2013) Post-transplant lymphoproliferative disorder: no relationship to recombinant human growth hormone use in Australian and New Zealand pediatric kidney transplant recipients. Pediatr Transplant 17:731-716

73. Rees L, Greene SA, Adlard P, Jones J, Haycock GB, Ridgen SP, Preece M, Chantler C (1988) Growth and endocrine function after renal transplantation. Arch Dis Child 63:1326-1332

74. Ghanem ME, Emam ME, Albaghdady LA, Bakr NI, Helal AS, Sadek EE, Sobh MA (2010) Effect of childhood kidney transplantation on puberty. Fertile Steril 94:2248-2252

75. Tainio J, Jahnukainen T, Nurmio M, Pakarinen M, Jalanko H, Jahnukainen T (2014) Testicular function, semen quality, and fertility in young men after renal transplantation during childhood and adolescence. Transplantation 98:987-993

76. Haffner D, Schüler U (2014) Metabolic bone disease after renal transplantation. Curr Opin Pediatr 26:198-206

77. Helenius I, Remes V, Salminen S, Valta H, Mäkitie O, Holmberg C, Palmu P, Tervahartiala P, Sarna S, Helenius M, Peltonen J, Jalanko $\mathrm{H}$ (2006) Incidence and predictors of fractures in children after solid organ transplantation: a 5-year prospective, population-based study. J Bone Miner Res 21:380-387

78. Valta H, Mäkitie O, Rönnholm K, Jalanko H (2009) Bone health in children and adolescents after renal transplantation. J Bone Miner Res 24:1699-1708

79. Bacchetta J, Ranchin B, Demède D, Allard L (2013) The consequences of pediatric renal transplantation on bone metabolism and growth. Curr Opin Organ Transplant 18:555-562

80. Ramirez-Cortes G, Fuentas-Valesco Y, García-Roca P, Guadarrama O, López M, Valverde-Rosas S, Velásquez-Jones L, Romero B, Toussaint G, Medeiros M (2009) Prevalence of metabolic syndrome and obesity in renal transplanted Mexican children. Pediatr Transplant 14:351-357
81. Mistnefes MM, Khoury P, McEnery PT (2002) Body mass index and allograft function in pediatric renal transplantation. Pediatr Nephrol 17:535-539

82. Sorof JM, Sullivan EK, Tejani A, Portman RJ (1999) Antihypertensive medication and renal allograft failure: a North American Pediatric Renal Transplant Cooperative Study report. J Am Soc Nephrol 10:1324-1330

83. Prokai A, Fekete A, Kis E, Reusz GS, Sallay P, Korner A, Wagner L, Tulassay T, Szabo AJ (2008) Post-transplant diabetes mellitus in children following renal transplantation. Pediatr Transplant 12:643-649

84. Oblak M, Kandus A, Mlinšek G, Buturović-Ponikvar J, Arnol M (2013) Increase in proteinuria after acute kidney graft rejection is associated with decreased graft function and survival. Transplant Proc 45:1453-1457

85. Johnson RJ, Warady BA (2013) Long-term neurocognitive outcomes of patients with end-stage renal disease during infancy. Pediatr Nephrol 28:1283-1291

86. Qvist E, Pihko H, Fagerudd P, Valanne L, Lamminranta S, Karikoski J, Sainio K, Rönnholm K, Jalanko H, Holmberg C (2002) Neurodevelopmental outcome in high-risk patients after renal transplantation in early childhood. Pediatr Transplant 6:53-62

87. Haavisto A, Korkman M, Holmberg C, Jalanko H, Qvist E (2012) Neuropsychological profile of children with kidney transplants. Nephrol Dial Transplant 27:2594-2601

88. Laakkonen H, Taskinen S, Rönnholm K, Holmbrg C, Sandberg S (2014) Parent-child and spousal relationships in families with a young child with end-stage renal disease. Pediatr Nephrol 29:289-295

89. Qvist E, Närhi V, Apajasalo M, Rönnholm K, Jalanko H, Almqvist F, Holmberg C (2004) Psychosocial adjustment and quality of life after renal transplantation in early childhood. Pediatr Transplant 8:120-125

90. Diseth TH, Tangeraas T, Reinfjell T, Bjerre A (2011) Kidney transplantation in childhood: mental health and quality of life of children and caregivers. Pediatr Nephrol 26:1881-1892

91. Haavisto A, Jalanko H, Sintonen H, Holmberg C, Qvist E (2011) Quality of life in adult survivors of pediatric kidney transplantation. Transplantation 92:1322-1326

92. Kärrfelt HM, Berg UB (2008) Long-term psychosocial outcome after renal transplantation during childhood. Pediatr Transplant 12:557-562

93. Anthony SJ, Pollock Barziv S, Ng VL (2010) Quality of life after pediatric solid organ transplantation. Pediatr Clin N Am 57:559-574

94. Tozzi A, Mazzotti E, Di Clommo VM, Dello Strologo L, Cuttini M (2012) Quality of life in a cohort of patients diagnosed with renal failure in childhood and who received renal transplant. Pediatr Transplant 16:840-845

95. Dharnidharka VR, Fiorina P, Harmon WE (2014) Kidney transplantation in children. N Engl J Med 371:549-558

96. Andreoni KA, Forbes R, Andreoni RM, Phillips G, Stewart H, Ferris M (2013) Age-related kidney transplant outcomes. Health disparities amplified in adolescence. JAMA Intern Med 173:1524-1532

\section{Answers to multiple-choice questions}

1) a

2) d

3) $b$

4) e

5) d 